\title{
Personalities in Physics
}

IN his presidential address to the Physical Society delivered on January 24, Lord Rayleigh gave a highly interesting and historically valuable account of some of his personal recol. lections of a number of eminent scientific men of recent times and of the circumstances in which they carried out their work.

"There is," he contended, "a difference of opinion as to how far personal idiosyncrasies and details of private life are worthy of record when they have little direct bearing on results. Usually such details of the lives of scientific workers are but scantily preserved; and to judge by the frequency with which the few available details are quoted and requoted, one may guess that most people are eager for them, and wish that contemporaries had handed them down to a greater extent than they have done. For my part, I think that the history of science is quite as much involved with the personalities of the men who have made it as is any other kind of history. The familiar process of digesting original memoirs into textbooks, however necessary, can only be accomplished at the expense of some sacrifice of true historical perspective ; and the limitation of knowledge and the narrowness of the basis on which generalisation rests are too often lost sight of in the process. To know something of the personalities of the men of science themselves, the conditions of their lives, and the point of view from which they worked, may often be a useful corrective to this tendency. Those who have had the good fortune to be in personal contact with the great workers of the generation above them should not neglect to record what they think may possibly be valued by posterity. There is no doubt that this duty has been too little regarded in the past. It is hard to realize when one is young that what we see to-day may be gone to-morrow and irretrievably forgotten the day after : and still harder to realize how eager posterity may be to know it."

Among many recollections of Kelvin in his later life, Lord Rayleigh spoke of his tireless mental activity, his insensitiveness to interruption especially when carrying out calculations in the famous 'green book', which was carried and used everywhere, in drawing-rooms, trains and hansom cabs, in the chair of the Royal Commission on Arsenical Poisoning from Beer (1901), and even on the platform of the British Association, where during a not very inspiring address its owner was observed to be busy on matters that he doubtless considered of greater significance. $\mathrm{He}$ spoke of Kelvin's efforts in the earlier days of his Glasgow professorship to encourage students to work in his laboratory at a time when it was very difficult to gain even the simplest practical acquaintance with the carrying out of experiments, although he seems to have had no other idea than that they should make themselves useful, seeing that he set Ramsay to work on removing the kinks from some old eopper wire. Reference was also made to his caution and careful thinking, his deep insight into the essentials of an engineering problem, his careful composition-he would sometimes pause for long periods until he had got the right word-his fondness for mechanical analogies and his consequent dissatisfaction with the electromagnetic theory of light, which he sometimes would not rank as a theory at all.

In an interesting comment on this theory, Lord Rayleigh pointed out, as Kelvin had many years ago pointed out to him, the apparently littleknown fact that Kirchhoff had shown some six years before Maxwell that the velocity of light could be derived from electrical measurements. Kelvin mentioned this in a conversation on Maxwell's theory as a reply to Lord Rayleigh's remark that at any rate it seemed a great step to have shown that the velocity of light could be derived from such measurements. Among other interesting details, Lord Rayleigh recalled Kelvin's curious taste for puns, his simple humour, his suggestion that a correspondent in an electrical journal had better be submitted to the action of the "silent discharge", his enthusiasm for experimental work, his courtesy, his inability to adjust his matter to the capacity of his audience, his violence against Home Rule, his dislike of motor-cars and his emphasis on the wisdom and necessity of the ten miles per hour speed limit, his scepticism about the practical possibility of the aeroplane, his fondness for the theatre, his boyishness and simple kindliness, his apparently complete unconsciousness of his success in life, and that great dignity and impressiveness which he could assume.

Lord Rayleigh then proceeded to deal with various reminiscences of the Royal Institution, making some reference to his father's work, partly earried out there, on the separation of argon from air. Of Sir James Dewar, he recalled the early liquefaction of air on a large scale, the liquefaction of hydrogen and the attempted liquefaction of helium, a triumph of which Dewar was robbed probably through using crude gas from the Bath spring instead of monazite, since the former contained neon which blocked the tubes of the liquefying apparatus. 
"From this point of view," said Lord Rayleigh, "it seems a considerable misfortune for British science that helium was ever found in the gas at the Bath spring. If Dewar had extracted his helium from monazite, as Kamerlingh Onnes did afterwards, he would probably have succeeded in the liquefaction. Nevertheless, his large-scale operations with the Bath gas may be considered the prototype of those modern ones which have led to the collection of helium in quantities adequate even for use in airships. It must have been an acute disappointment to Dewar that he was outstripped in the race to liquefy helium. But he took it with a good grace and himself gave an exposition of Kamerlingh Onnes' work at the British Association meeting at Dublin in 1908."

Lord Rayleigh spoke also of Dewar's refusal to admit the danger of the work on the liquefaction of gases ; his apparently grudging admission that it was a little "tricky" was no overstatement considering that Lennox and Heath, his two assistants, each lost an eye in the course of the work. He referred also to Dewar's unorthodox engineering, his neglect of proper safety factors, his dislike of unannounced visitors, his secrecy with regard to his laboratory work-he civilly begged to be excused showing his laboratory to Kamerlingh Onnes, saying that then no awkward question could arise-his quarrelsome but essentially kind-hearted nature (was it Scots dourness in an exceptional degree ?), his sleeplessnesshe was glad to get even three hours sleep a night his amateur pharmacology, his generosity to those in need and his refusal to accept thanks, and his curious and almost impenetrable mental processes. Dewar's earliest publication of the idea of a vacuum vessel dates so far back as 1874, and the suggestion that he was anticipated has no justification: "Dewar gave his invention of the vacuum flask freely to the world, and never made a penny by it, though he might have realised a fortune." If only, as Lord Rayleigh remarked, vacuumjacketed vessels had come to be called Dewar flasks instead of thermos flasks, their inventor's fame would doubtless have penetrated to a very wide public. (But is it really too late for us to place the 'Dewar flask' alongside the 'Davy lamp', another invention freely given to the world?)

Of Dewar's extraordinarily interesting chief assistant, Robert Lennox, Lord Rayleigh had much to say. Lennox worked with Dewar for twenty-seven years (1881-1908) and, as Lord Rayleigh remarked, his "services to science have not been sufficiently recorded". Lennox, it appears, had some training in engineering under Prof. James Thomson of Glasgow and had been chemical assistant to Dittmar at Glasgow Technical College; although he had not taken a science degree, his general scientific capacity was far beyond that of the ordinary graduate. Lennox, it is believed, said Lord Rayleigh,

"was mainly if not wholly responsible for the design of the compressors and liquefiers in their engineering aspect. By a rather curious arrangement they were made by a firm, Lennox, Reynolds and Fyfe, of which he was the leading spirit. . . . But how he was able to find time for this while he was in regular attendance at the Royal Institution it is hard to understand. He must have relinquished all leisure and recreation. . . . The large air pumps used in Dewar's laboratory for evaporating liquid air and liquid hydrogen in vacuo were of his design and construction. They were of the rotatory type with an eccentric barrel and sliding feathers, and so far as I know they were the first successful air pumps of this design, though the fundamental idea as applied to water pumps is a very old one."

Dewar himself, of all men the least given to passing the base coin of insincerity, wrote that but for Lennox's "invaluable aid . . . engineering skill, manipulative ability, and loyal perseverance" the successful liquefaction of hydrogen "might have been indefinitely delayed". Lord Rayleigh spoke also of Lennox's stoic courage, his confidence and his cynical wit. Lennox was interested in an acid-resisting alloy, the peculiarities of which had led a puzzled workman to remark "t'aint iron", whereupon the trade name of "Tantiron" was adopted. "It is curious," Lennox remarked afterwards, "that so many analysts should find tantalum in it."

"A serious accident," added Lord Rayleigh, "occurred when he was trying the generation of acetylene under pressure, with a view to storing it liquid in cylinders. There was a violent explosion. Sir Joseph Petavel was in the next room. The first thing he heard after the explosion itself was Lennox's voice saying 'Look out, you men, put out the gas in there'. Next, he saw Lennox, his face streaming with blood and one of his eyes torn to pieces and the fragments spread all over his face, but quite calm. His first thought had been to prevent any further accident from the escaping acetylene."

Passing to Sir William Crookes, Lord Rayleigh remarked on his resemblance to Faraday in his early life, his work, his methods and his equipment; of his scrupulous tidiness, of the many absolutely new 'hares' that he started in scienceaccording to Kelvin, more than any of his scientific contemporaries had started-his friendliness, his resolution when action was called for, his reserve when pressed for information and of his great annoyance at having missed the discovery of X-rays. 
"According to the account he gave in my hearing," said Lord Rayleigh, "he had definitely found previously unopened boxes of plates in his laboratory to be fogged for no assignable reason, and, acting I suppose in accordance with the usual human instinct of blaming someone else when things go wrong, he complained to the makers, who naturally had no satisfactory explanation to offer. I believe it was only after Röntgen's discovery that he connected this with the use of highly exhausted vacuum tubes in the neighbourhood. He had, at least, less to reproach himself for than another English man of science, who, it is said, knew that high vacuum discharge tubes were apt to fog photographic plates anywhere near them, and only drew the moral that the plates should be stored elsewhere".
In conclusion, Lord Rayleigh spoke of Sir Arthur Schuster, until recently one of the now fast diminishing band who derived personal inspiration from Clerk Maxwell. Schuster showed complete indifference to the practical applications of science and the plaudits of the gallery. $\mathrm{He}$ always retained an open mind to scientific 'heresy'. His reserve and sensitiveness received a great shock at the treatment he met with in the early days of the Great War. He narrowly missed the discovery of the Zeeman effect, and was diverted by Röntgen's discovery from provisional conclusions on his measurements of the deflection of eathode rays in a magnetic field, in both of which problems "he had the root of the matter".

Douglas McKie.

\section{Animal Intelligence}

$\mathrm{T}$ WO lectures on animal intelligence were recently given at the Royal Society of Arts* by Dr. David Katz, formerly professor of psychology and education at the University of Rostock, Mecklenburg. Although addressed to a juvenile audience, the matter and form of Dr. Katz's lectures raise serious issues regarding the scientific study of animal behaviour, and for that reason no less than for their attractive quality, the lectures merit close consideration. Their substance and sequence were briefly as follows.

Intelligence is defined as the capacity to adapt to new conditions. In estimating its manifestations in animals, we can easily be misled by spurious performances-as is amply shown in the history of the Elberfeld counting horses, whose activities were such as to persuade the gullible that horses are able to solve even the cube roots of numbers running into millions. The study of animal behaviour has, therefore, to be approached with circumspection, and no simple answer can be given to the question of the comparative merits of animal and human intelligence. The worlds in which animals live are often so different from our own-.. mainly because of differences in sensory capacities -that it is frequently impossible to find any means of explaining their activities. For example, the manner in which some animals accurately find their way from one place to another, often hundreds of miles distant, remains, in spite of much investigation, a complete mystery.

An analysis of animal intelligence demands a recognition of three forms of behaviour. The first is instinctive behaviour, which is perhaps best

-J. Roy. Soc. Arts, 84, 281. manifested in the insect world. "Instinct,". stated Dr. Katz, "is what a whole species has learned to do, as distinct from what an individual member of the species learns for itself." What an animal learns for itself is a higher form of adaptation, and learning through 'trial and error' thus constitutes the second form of behaviour. It is manifested, so far as is known, by most living creatures. The third and highest form of animal intelligence is adaptation, through insight, by the exercise of reason. Behaviour which merits such description occurs only amongst the larger apes, and is exemplified by the well-known instance of the chimpanzee who, in order to reach a banana suspended from a ceiling, climbed on to boxes which it stacked for the purpose.

In appraising Dr. Katz's lectures, it has to be remembered that they were addressed to a juvenile audience, for that fact probably explains why it was that the discourse followed the classical lines laid down for such discussions towards the end of the last century. The question arises, however, whether or not the scheme still provides an adequate framework for the numerous facts about animal behaviour which have been gathered experimentally during the past fifty years, and whether the time has not been reached when even popular reviews of the subject should expand less on its traditional issues, such as instinct, about whose inner nature little or nothing is known, and concentrate more on forms of behaviour the scientific analysis of which has added a little light to the general mystery by which much of the subject is encompassed.

The shortcoming of the classical approach 